\title{
Effects of Irregular Bridge Columns and Feasibility of Seismic Regularity
}

\author{
Abey E. Thomas ${ }^{1}$ \\ Received: 13 August 2015/Accepted: 26 April 2018/Published online: 12 May 2018 \\ (C) The Institution of Engineers (India) 2018
}

\begin{abstract}
Bridges with unequal column height is one of the main irregularities in bridge design particularly while negotiating steep valleys, making the bridges vulnerable to seismic action. The desirable behaviour of bridge columns towards seismic loading is that, they should perform in a regular fashion, i.e. the capacity of each column should be utilized evenly. But, this type of behaviour is often missing when the column heights are unequal along the length of the bridge, allowing short columns to bear the maximum lateral load. In the present study, the effects of unequal column height on the global seismic performance of bridges are studied using pushover analysis. Codes such as CalTrans (Engineering service center, earthquake engineering branch, 2013) and EC-8 (EN 1998-2: design of structures for earthquake resistance. Part 2: bridges, European Committee for Standardization, Brussels, 2005) suggests seismic regularity criterion for achieving regular seismic performance level at all the bridge columns. The feasibility of adopting these seismic regularity criterions along with those mentioned in literatures will be assessed for bridges designed as per the Indian Standards in the present study.
\end{abstract}

Keywords Bridge · Irregular columns · Pushover analysis - Seismic performance .

Seismic regularity

\section{List of symbols}

$r_{i} \quad$ Local force reduction factor

\author{
Abey E. Thomas \\ abeyethomas@yahoo.com \\ 1 College of Engineering Aranmula, Pathanamthitta, India
}

$K_{i}^{e} \quad$ Smaller effective bent or column stiffness

$K_{j}^{e} \quad$ Larger effective bent or column stiffness

$\rho_{\text {steel }, l} \quad$ Longitudinal reinforcement ratio of long columns

$\rho_{\text {steel }, s} \quad$ Longitudinal reinforcement ratio of short columns

$H_{l} \quad$ Height of long column

$H_{s} \quad$ Height of short column

$A_{g} \quad$ Gross cross-sectional area

$p_{t} \quad$ Longitudinal reinforcement percentage

O Operational

IO Immediate occupancy

LS Life safety level of performance

\section{Introduction}

Seismic vulnerability of bridges increases with the presence of irregularity [1]. The global seismic performance of the bridges is significantly affected by the presence of irregular columns. The displacement ductility demand for shorter columns in bridges with unequal column height is considerably higher than the longer columns during earthquake, owing to the similarity in column cross-sections considering aesthetics and Force Based Design (FBD) methodology adopted in its design. Hence, the failure criteria for such irregular bridges mainly depend on the shear and flexural capacity of its shorter columns. Modern design codes take due consideration to prevent such unbalanced or uneven distribution of inelastic response throughout the structure which may lead to increased damage in its stiffer elements and increased column torsion. The design approach adopted by codes such as EC-8 [2] and CalTrans [3], is to have a balanced damage and near simultaneous collapse of all columns in a given bridge at a given extreme 
target demand, irrespective of column heights. This concept of regularising the performance level of bridge columns for a specified seismic hazard level is widely known as 'seismic regularity' of bridges. Different codes use different concepts for achieving regularity of performance in bridge columns. EC-8 [2] follows a regularity criterion based on the relative strength of columns i.e. moment capacity and demand. While, CalTrans [3] stipulates a regularity criterion based on the effective stiffness of bridge columns. But, still the seismic design and response prediction of irregular bridges supported on unequal column heights represent a challenging problem that is yet to be effectively addressed by the seismic code provisions worldwide [4].

In the present study, the global seismic performance of four PSC box-girder bridges with varied levels of irregularity is assessed through Static Pushover Analysis (SPA). The bridges considered are of three equal spans and the columns are monolithically connected to the bridge super structure similar to that of a semi-integral bridge. At abutments, the deck is assumed to be supported on sliders permitting free translational movement along the longitudinal direction, while keeping all other movements fixed. Here, the column height at Bent-1 (B-1) is varied relative to that of Bent-2 (B-2), as shown in Fig. 1, in the order of $1,0.8,0.65$ and 0.5 , without changing the spacing of the confinement reinforcement. SPA gives static pushover curves identifying different limit states and ductility capacity. The studies are conducted on bridges in their longitudinal direction as it is the predominant direction. The paper also aims at reviewing the various seismic regularity criterions specified in modern codes and literatures and checking the feasibility of introducing them in bridges designed as per IRC 112 [5].

\section{Theory}

EC-8 (EN 1998-2, [2]) recommends a seismic regularity criterion based on column relative strength. Bridges are considered regular, when the condition in (1) is satisfied:

$\rho=r_{\max } / r_{\text {min }} \leq \rho_{o}$.

where $r_{\min }=\operatorname{minimum}\left(r_{i}\right)$ and $r_{\max }=\operatorname{maximum}\left(r_{i}\right)$ for all ductile columns $i ; r_{i}$ is the local force reduction factor,

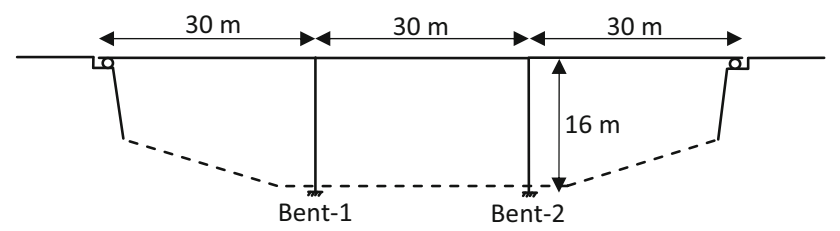

Fig. 1 Bridge geometry used in the study of seismic irregularity
$r_{i}=q\left(M_{E d, i} / M_{R d, i}\right) ; q$ is the behaviour factor; $M_{E d, i}$ and $M_{R d, i}$ are the maximum value of design moment (i.e., demand) and the maximum value of design flexural resistance, respectively, under the seismic load combinations at the intended location of the plastic hinge of ductile column $i ; \rho_{o}$. is defined as a limit to ensure that sequential yielding of the ductile columns shall not cause unacceptably high ductility demands on one column relative to the other. Code recommends a value of 2 , for $\rho_{o}$. It also stipulates an exemption of one or more ductile columns from the above calculation of $r_{\min }$ and $r_{\max }$, if the sum of their shear contributions does not exceed $20 \%$ of the total seismic shear in the direction under consideration.

CalTrans [3] follows a balanced stiffness approach in achieving seismic regularity in bridges. For constant width bridge deck, it suggests a minimum relative effective stiffness as in (2).

$K_{i}^{e} / K_{j}^{e} \geq 0.5$

where $K_{i}^{e}$ is the smaller effective bent or column stiffness and $K_{j}^{e}$ is the larger effective bent or column stiffness. The consequence of not meeting the minimum relative stiffness requirement includes; increased damage in stiffer elements, unbalanced distribution of inelastic response throughout the structure and increased column torsion generated by rigid body rotation of the superstructure. As the relative effective stiffness is a more improved criterion than the strength approach for seismic regularity of bridges [6], in the present study, among the codal provisions, the regularity criterion stipulated by CalTrans [3] is assessed for its feasibility for considerations in IRC provisions.

In cases where the relative stiffness approach proposed by CalTrans [3] remains impractical, engineers do have to design column in such a way that, the longer column stiffness is higher than what is acquired in FBD approach. This can be achieved by providing a larger column dimension or by assigning higher percentage of longitudinal reinforcement in longer columns. In most of the cases, the column dimensions are kept the same considering the aesthetic appearance of bridges and hence, increasing the column longitudinal reinforcement ratio is the most practical solution for increasing the stiffness of the longer columns. Studies conducted by Guirguis and Mehanny [4] recommend a relative ratio of column reinforcement for achieving near simultaneous collapse of bridge columns as shown in (3). Hence, in this paper the feasibility of using the seismic regularity criterion proposed by Guirguis and Mehanny [12] is also evaluated for bridges designed as per the Indian Standards.

$\rho_{\text {steel }, l} / \rho_{\text {steel, } s}=\left(H_{l} / H_{s}\right)^{4.2}$ 
here $\rho_{\text {steel, }, \text { and }} \rho_{\text {steel,s }}$ are the longitudinal reinforcement ratio of long and short columns, respectively, and $H_{l}$ and $H_{s}$ are their corresponding heights.

\section{Model Details}

In the present study, three dimensional (3D) finite element bridge models are used in assessing the influence of column irregularity on the global seismic response of bridges. Three span PSC box-girder bridges with individual span length of $30 \mathrm{~m}$ are used for the comparative study. The deck is cast monolithic with the columns at bents, and at abutments it is provided with sliders permitting translational motion along the longitudinal direction. Super-Imposed Dead Load (SIDL) of $2 \mathrm{kN} / \mathrm{m}$ is provided for considering the mass of wearing course and other secondary elements which does not contribute additional stiffness to the structure. The bridge models considered are of single column bents and the columns at both bents are of the same cross-sectional dimension $1.8 \mathrm{~m} \times 3.6 \mathrm{~m}$. The height of column at B-1 is varied relatively from $0.5,0.65$, 0.8 and 1 with respect to the column at B-2, which is of $16 \mathrm{~m}$ height. Hence, the column at B-1 will have heights of 8, 10.4, 12.8 and $16 \mathrm{~m}$, respectively for Relative Height $(\mathrm{RH})$ ratio of $0.5,0.65,0.8$ and 1 . The confinement reinforcement provided is an essential factor determining the ductility of bridges. In the present study, lateral ties of $12 \mathrm{~mm}$ diameter at a spacing of $100 \mathrm{~mm}$ are provided, satisfying the minimum shear requirements as per IRC 112 [5]. The longitudinal reinforcement ratio is estimated for a load combination corresponding to VIth combination satisfying the service condition as mentioned in IRC 6 [7] with live load taken as per Table 2 of IRC 6 [7]. The IRC 112 designed bridge columns have a minimum longitudinal reinforcement percentage $\left(p_{t}\right)$ of $0.2 \%$ of gross cross-sectional area $\left(A_{g}\right)$, while the corresponding minimum $p_{t}$ as per CalTrans [3] is $1 \%$ of $A_{g}$. The grade of steel and concrete are kept as Fe 415 and M40, respectively for all the bridge models considered. The demand spectra used for the estimation of seismic load corresponds to a Zone factor $(Z)$ of 0.36 and an Importance factor $(I)$ of 1.5 corresponding to 'Large Critical' bridges as per IRC 6 [7]. The response Reduction factor $(R)$ for columns is taken as 3 as per IRC 6 (Amendment, August 2014). Dimension and geometry detail of the bridge deck used is shown in Fig. 2.

\section{Effects of Column Irregularity}

The present study demonstrates the effects of unequal column height in the global seismic performance of bridges using pushover analysis in SAP2000 NL. The column base shear, base moment, top displacement and performance levels at both Design Basis Earthquake (DBE) and Maximum Considered Earthquake (MCE) levels are used in assessing the influence of irregular columns on bridges. As the columns are designed based on FBD, the results also represent the intrinsic problems which may be associated with the design methodology adopted [8].

The pushover curve in Fig. 3 clearly portrays the increase in stiffness and reduction in displacement ductility as the irregularity in column height increases, irrespective of the column minimum reinforcement adopted. This is a definite indication that, shorter column determines the seismic performance of irregular bridges. But, for an improved performance of such irregular bridges it is imperative to have a more balanced behaviour, where-in longer columns are also effective in resisting lateral loads. This is commonly termed as 'seismic regularity' in modern bridge design codes. As mentioned earlier, two approaches are most commonly adopted for achieving similar performance levels in columns of irregular bridges, they are; balanced strength and balanced stiffness approach. In the present study, the latter approach and its feasibility will be discussed in detail.

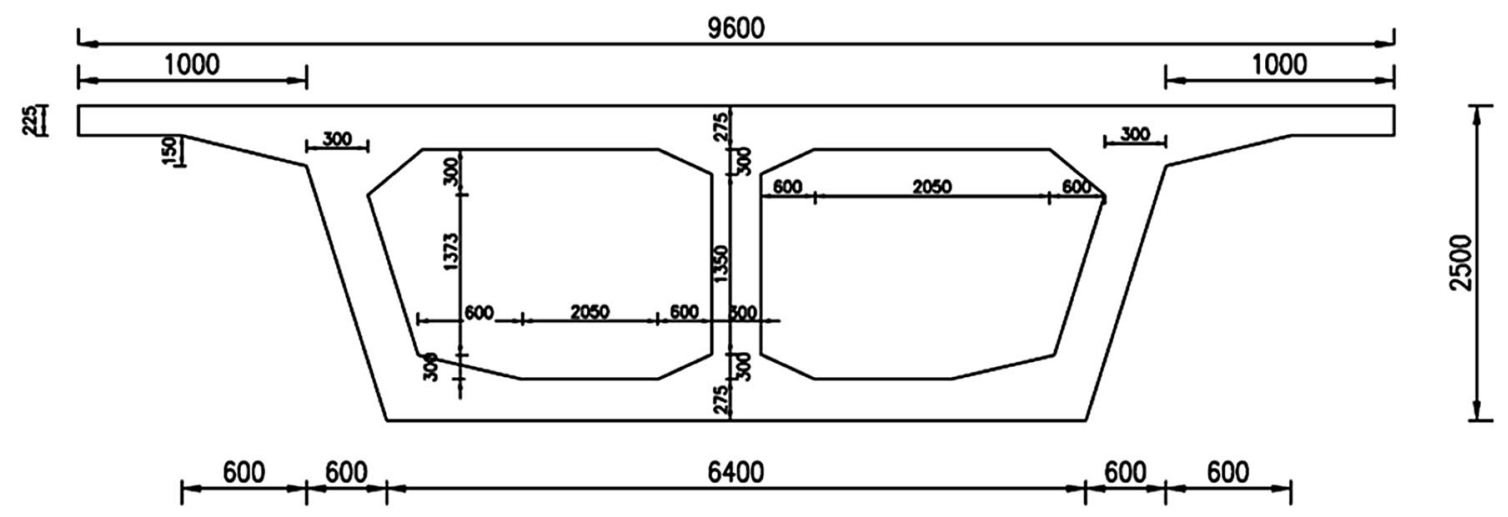

Fig. 2 Geometry and dimension detail of the deck (all dimensions in mm) 
Fig. 3 Pushover curve
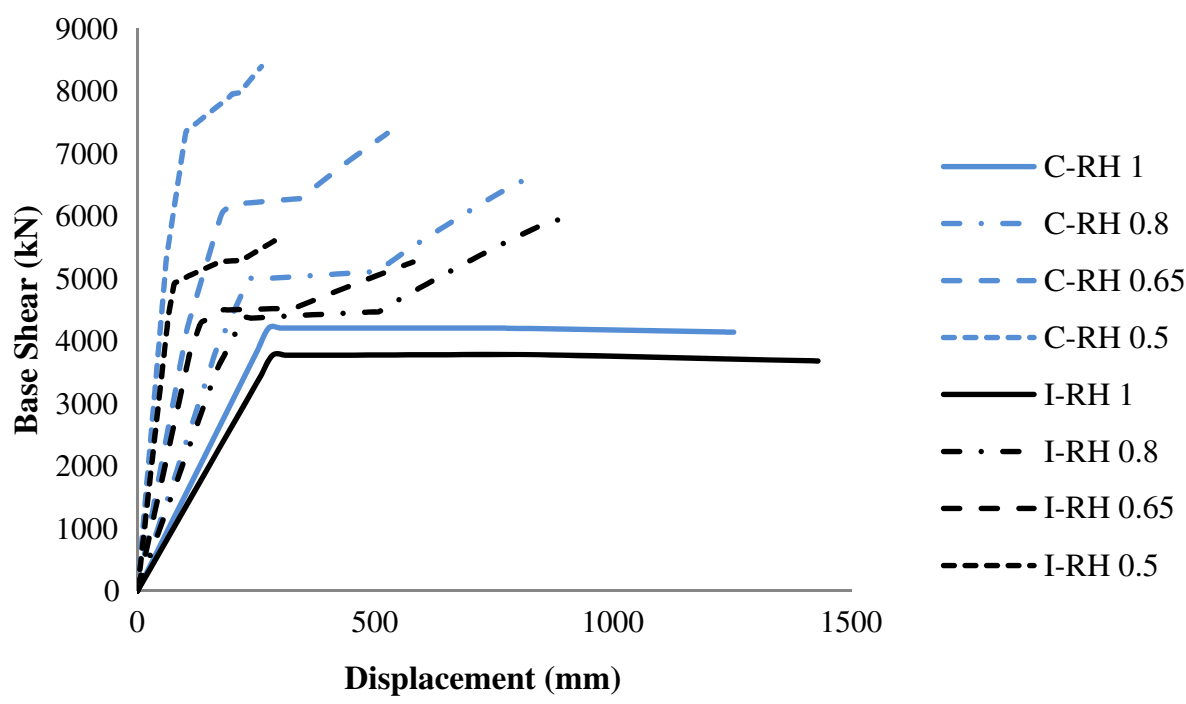

Displacement (mm)

Table 1 Demand values at DBE and MCE levels with varied RH of columns

\begin{tabular}{|c|c|c|c|c|c|c|c|c|c|c|}
\hline \multirow[t]{3}{*}{ Relative column height $(\mathrm{RH})$} & \multicolumn{5}{|l|}{ DBE } & \multicolumn{5}{|l|}{$\mathrm{MCE}$} \\
\hline & \multirow[t]{2}{*}{ Disp. (mm) } & \multicolumn{2}{|c|}{ Base shear $(\mathrm{kN})$} & \multicolumn{2}{|c|}{ Base moment $(\mathrm{kNm})$} & \multirow[t]{2}{*}{ Disp. (mm) } & \multicolumn{2}{|c|}{ Base shear $(\mathrm{kN})$} & \multicolumn{2}{|c|}{ Base moment $(\mathrm{kNm}$} \\
\hline & & B-1 & B-2 & B-1 & B-2 & & B-1 & B-2 & B-1 & B-2 \\
\hline 1 & 180 & 2103.5 & 2103.5 & $33,656.5$ & $33,656.5$ & 316 & 2103.5 & 2103.5 & $33,656.5$ & $33,656.5$ \\
\hline 0.8 & 146 & 3214.4 & 632.7 & $34,999.7$ & $16,267.8$ & 256 & 4041.3 & 957.2 & $43,713.3$ & $23,331.1$ \\
\hline 0.65 & 109 & 4549.5 & -81.9 & $37,653.5$ & 8350.8 & 195 & 5960.6 & 221.1 & $49,314.9$ & $16,212.4$ \\
\hline 0.5 & 70 & 6460.6 & -623.2 & $39,675.1$ & 2038.1 & 128 & 8032.9 & -519.7 & $49,291.4$ & 6656 \\
\hline
\end{tabular}

In Fig. 3, legend ' $C$ ' represents the capacity curve of columns designed with minimum $p_{t}$ as per CalTrans [3] and legend ' $I$ ' represents the capacity curve of columns designed as per IRC 112 [5].

As evident from Table 1, the increased stiffness in shorter columns of irregular bridges leads to an amplified base shear and moment values in it compared to longer columns which are more flexible. The column base moment values of longer columns indicate that, as the $\mathrm{RH}$ value decreases from 1 to 0.5 , the amount of reinforcement required in longer columns is greatly reduced in comparison to the shorter columns. It can also be inferred that, the longer columns remain almost passive in its lateral load resistance once the $\mathrm{RH}$ ratio is below 0.8 . The reduction in column top displacement, and hence ductility capacity, in bridges with higher level of column irregularity as depicted in Fig. 4 further shows the ineffectiveness of longer columns in lateral load resistance. The performance level of columns in both bents at DBE and MCE levels are tabulated in Tables 2 and 3, respectively, for those designed in accordance with IRC 112 [5] and with modified $p_{t}$ in accordance with CalTrans [3]. The results show that, for columns designed in accordance with IRC 112, seismic regularity can't be achieved even at a $\mathrm{RH}$ ratio of 0.8 (thus

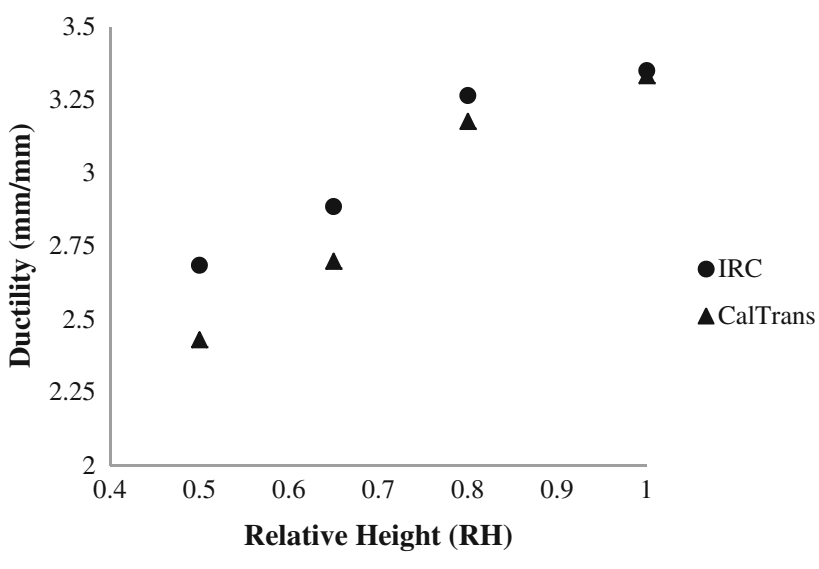

Fig. 4 Variation in displacement ductility

confirming the results obtained from EC-8 as specified in "Feasibility of Balanced Stiffness Approach" section) while for columns with modified $p_{t}$, seismic regularity as specified by balanced stiffness approach can be achieved. Although Indian codes seldom specifies any Performance Objective (PO) to be achieved based on the functional importance of bridges as in AASHTO [9], it is highly essential to assess whether the functionality of the bridges 
Table 2 Performance levels of columns designed as per IRC

\begin{tabular}{llllll}
\hline Relative column height $(\mathrm{RH})$ & \multicolumn{4}{l}{ Performance levels } \\
\cline { 2 - 3 } & \multicolumn{2}{l}{$\mathrm{DBE}$} & & $\mathrm{MCE}$ & \\
\cline { 2 - 3 } \cline { 5 - 6 } & $\mathrm{B}-1$ & $\mathrm{~B}-2$ & & $\mathrm{~B}-1$ & $\mathrm{~B}-2$ \\
\hline 1 & $\mathrm{O}$ & $\mathrm{O}$ & $\mathrm{O}$ & $\mathrm{O}$ \\
0.8 & $\mathrm{O}$ & $\mathrm{O}$ & $\mathrm{IO}$ & $\mathrm{O}$ \\
0.65 & $\mathrm{O}$ & $\mathrm{O}$ & $\mathrm{LS}$ & $\mathrm{O}$ \\
0.5 & $\mathrm{O}$ & $\mathrm{O}$ & $\mathrm{LS}$ & $\mathrm{O}$ \\
\hline
\end{tabular}

$O$ Operational, $I O$ immediate occupancy, $L S$ life safety level of performance

Table 3 Performance levels of columns with modified minimum $p_{t}$ as per CalTrans

\begin{tabular}{|c|c|c|c|c|}
\hline \multirow[t]{3}{*}{ Relative column height $(\mathrm{RH})$} & \multicolumn{4}{|c|}{ Performance levels } \\
\hline & \multicolumn{2}{|c|}{$\mathrm{DBE}$} & \multicolumn{2}{|c|}{ MCE } \\
\hline & B-1 & B-2 & B-1 & B-2 \\
\hline 1 & $\mathrm{O}$ & $\mathrm{O}$ & $\mathrm{O}$ & $\mathrm{O}$ \\
\hline 0.8 & $\mathrm{O}$ & $\mathrm{O}$ & $\mathrm{O}$ & $\mathrm{O}$ \\
\hline 0.65 & $\mathrm{O}$ & $\mathrm{O}$ & IO & $\mathrm{O}$ \\
\hline 0.5 & $\mathrm{O}$ & $\mathrm{O}$ & IO & $\mathrm{O}$ \\
\hline
\end{tabular}

is attained by simply applying an Importance factor (I) while designing. AASHTO [9] recommends an 'IO' level of performance at MCE and ' $\mathrm{O}$ ' level of performance at DBE for 'Critical' bridges. The performance levels in Table 2 indicates that, the PO to be satisfied for 'Large Critical' bridges (which is in par with 'Critical' bridges specified in AASHTO [9]) seems to be violated while the $\mathrm{RH}$ ratio falls below 0.8 when designed with a minimum $p_{t}$ as per IRC 112. But, this can be overcome by providing minimum $p_{t}$ as recommended by CalTrans or AASHTO, as is evident from Table 3 . This also shows the discrepancy in adopting a simplified $I$ value for designing bridges with varied functional importance and thus emphasising the importance of analysis procedures like Capacity Spectrum Analysis (CSA) for assessing the PO for bridges with varied functional importance. Results tabulated in Table 3 further advocates that, any column irregularity beyond an RH ratio of 0.8 will lead to considerable changes in column performance levels even if modified $p_{t}$ as per CalTrans is used. Hence, seismic regularity in such bridges can longer be achieved.

\section{Feasibility of Balanced Stiffness Approach}

Although the EC-8 recommended balanced strength approach is a viable solution for achieving seismic regularity, it is found to be a more conservative approach compared to CalTrans specified balanced stiffness approach. Following the balanced strength approach, the $\rho$ value as in (1) obtained for RH ratios of 1, 0.8, 0.65 and 0.5 are respectively, 1, 2.15, 4.52 and 10.47. This means an RH ratio of 0.8 is not a permissible value as per EC- 8 recommendations, which is in par with the results tabulated in Table 2. But, most of the bridges crossing steep valleys may encounter an $\mathrm{RH}$ value of at least 0.8. Also, during seismic action as most of the structures will undergo inelastic excursions, it is better to adopt effective stiffness approach than strength approach in seismic design [10-14].

For satisfying the relative stiffness condition proposed by CalTrans [3] for balanced stiffness and hence seismic regularity in bridges, the shorter column height shall be equal to or more than the cube root of 0.5 times the cube of the longer column height. In the present study, as the column at B-2 is of $16 \mathrm{~m}$ height, the least permissible height of column at B-1 is $12.7 \mathrm{~m}$, as per CalTrans [3]. Which is found to be absolutely correct based on the results tabulated in Table 3, with modified minimum $p_{t}$ values. Thus, for achieving seismic regularity in bridges the balanced stiffness approach is recommendable to Indian codes also, provided the minimum column $p_{t}$ is $1 \%$ instead of $0.2 \%$, as mentioned in IRC 112 [5]. The present recommendation for increasing the minimum $p_{t}$ of columns is also in par with IS 1893 Part 3 (2009), draft code, which stipulates a minimum column $p_{t}$ of $0.8 \%$ of $A_{g}$ in section A-3 for ensuring capacity design.

Apart from the above mentioned balanced stiffness approach, CalTrans [3] also recommends the following techniques for achieving near simultaneous collapse of all bridge columns at a specified target demand level, which can be stipulated in the Indian Codal provision also.

- Adjust effective column lengths.

- Modify end fixities.

- Reduce/redistribute superstructure mass.

- Add or relocate columns.

- Modify the hinge/expansion joint layout.

- Incorporate isolation bearings or dampers.

However, the details for proving the validity of these techniques are not apparent in CalTrans also, and hence need further research.

\section{Feasibility of Seismic Regularity Criterion Proposed by Guirguis and Mehanny}

The relative column reinforcement ratio proposed by Guirguis and Mehanny [12] gives the insight that, adopting FBD methodology for irregular bridges is not a viable option, as the reinforcement ratio in longer columns goes on decreasing with the reduction in $\mathrm{RH}$ ratio. But, the 
Table 4 Demand values with modified reinforcement ratio at B-2

\begin{tabular}{|c|c|c|c|c|c|c|c|c|c|c|}
\hline \multirow[t]{3}{*}{ Relative column height $(\mathrm{RH})$} & \multicolumn{5}{|l|}{ DBE } & \multicolumn{5}{|l|}{ MCE } \\
\hline & \multirow[t]{2}{*}{ Disp. (mm) } & \multicolumn{2}{|c|}{ Base shear $(\mathrm{kN})$} & \multicolumn{2}{|c|}{ Base moment $(\mathrm{kNm})$} & \multirow[t]{2}{*}{ Disp. $(\mathrm{mm})$} & \multicolumn{2}{|c|}{ Base shear $(\mathrm{kN})$} & \multicolumn{2}{|c|}{ Base moment $(\mathrm{kNm})$} \\
\hline & & B-1 & B-2 & B-1 & B-2 & & B-1 & B-2 & B-1 & B-2 \\
\hline 0.65 & 87 & 4894.4 & 1142.1 & $35,341.9$ & $33,832.7$ & 162 & 6884 & 2494.8 & $49,161.7$ & 62,348 \\
\hline 0.5 & 52 & 8025.3 & 1320.9 & $38,447.2$ & $46,889.9$ & 97 & $11,720.2$ & 3245.7 & $53,540.8$ & $92,152.7$ \\
\hline
\end{tabular}

Table 5 Performance levels with modified reinforcement ratio at B-2

\begin{tabular}{|c|c|c|c|c|}
\hline \multirow[t]{3}{*}{ Relative column height $(\mathrm{RH})$} & \multicolumn{4}{|c|}{ Performance levels } \\
\hline & \multicolumn{2}{|l|}{ B-1 } & \multicolumn{2}{|l|}{ B-2 } \\
\hline & DBE & MCE & DBE & MCE \\
\hline 0.65 & $\mathrm{O}$ & $\mathrm{O}$ & $\mathrm{O}$ & $\mathrm{O}$ \\
\hline 0.5 & $\mathrm{O}$ & $\mathrm{O}$ & $\mathrm{O}$ & $\mathrm{O}$ \\
\hline
\end{tabular}

feasibility of the expression proposed in (3) for practical application needs to be validated for all bridge types, before using the same. As per the expression shown in (3), the reinforcement ratio in columns at B-2 for bridges with RH value of 0.65 and 0.5 are respectively, 6.11 and $18.38 \%$, which are not practical. A theoretical comparison of the demand values and performance levels of the above two bridge models are tabulated in Tables 4 and 5, respectively. The results indicate that, theoretically the expression provided in (3) meets the seismic regularity criterion for bridges with unequal column height, as the performance levels obtained from CSA remains same for columns in both bents at DBE and MCE level of seismic hazard.

\section{Comments on Minimum $p_{t}$ Recommended by IRC 112}

The lower limit on the column reinforcement reflects the traditional concern for the effect of time-dependent deformations as well as the desire to avoid sizeable difference between the flexural cracking and yield moments. The IRC 112 specified minimum $p_{t}$ for columns is $0.2 \%$, while many International Standards like ACI 318, AASHTO LRFD, CalTrans etc. stipulates a minimum $p_{t}$ of $1 \%$ on columns. The results discussed on irregular columns and the necessary conditions for achieving seismic regularity in the previous sections, emphasise the need for an increase in minimum $p_{t}$ for columns in Indian Standards also. Halvorsen [15] found that, columns with less than one percent steel have not exhibited good ductility. Numerical and experimental tests conducted by Ziehl et al. [16] for varied grade of concrete and loading ratio (i.e. live load to dead load) values found that, for the lower bound value of creep coefficients, the minimum $p_{t}$ can be brought down from $1 \%$ while at the higher bounds, the $p_{t}$ required is still more than $1 \%$. If the worst case is assumed for these factors, the minimum amount of steel that is needed in nearly all the cases to preclude passive yielding of longitudinal reinforcement is more than one percent of the gross area of cross section.

\section{Summary and Conclusions}

Among the various geometrical irregularities, bents with unequal column height remain one of the most common irregularities owing to the uneven terrain the bridge may have to surpass. The inherent discrepancies associated with FBD methodology makes it impractical to achieve seismic regularity in bridges with irregular column height, which is desirable. The column irregularity also makes the slender columns passive in seismic resistance and thereby subjecting the shorter columns to carry a significant percentage of the base shear, which may lead to even shear failure in shorter columns rather than flexural failure which is desired. Presently the Indian Standards is silent about the design recommendations on bridges with irregular columns, which in fact is very essential. The present study highlight the effects of column irregularity on the global seismic performance of equal span semi-integral bridges through pushover analysis and evaluate the feasibility of achieving regularity in seismic performance by adopting the recommendations proposed by CalTrans [3] and by Guirguis and Mehanny [12]. Based on the study following conclusions are drawn:

1. There is a need for specific design recommendations for bridges with unequal column height in the Indian Standards.

2. Longer columns of bridges with unequal column height are found to remain passive to seismic resistance below an $\mathrm{RH}$ ratio of 0.8 and the reinforcement requirement in such columns is considerably low, while adopting FBD methodology.

3. Reviewing the inherent discrepancies associated with FBD methodology it seems that, there is a need for adopting Displacement Based Design (DBD) methodology in Indi Standards also, as in modern codes. 
4. The balanced stiffness approach specified by CalTrans [3] can be used in the Indian codes also, provided, the minimum longitudinal reinforcement percentage for columns is increased to $1 \%$ of the gross cross-sectional area.

5. The minimum percentage of longitudinal reinforcement in columns prided in IRC 112 [5] needs a reevaluation in comparison with AASHTO [9], ACI 318 (2008) and CalTrans [3], considering bridges with unequal column height, loading ratio (i.e. live load to dead load ratio), creep and shrinkage effects.

\section{References}

1. R. Akbari, Cyclic response of RC continuous span bridges with irregular configuration in longitudinal direction. Struct. Infrastruct. Eng. (2010). https://doi.org/10.1080/15732479.2010. 510528

2. Comité Européen de Normalisation, EC 8 - CEN, EN 1998-2: Design of Structures for Earthquake Resistance. Part 2: Bridges (European Committee for Standardization, Brussels, 2005)

3. California Department of Transportation, Seismic Design Criteria Version 1.7. Engineering Service Center, Earthquake Engineering Branch, Sacramento, CA, 2013

4. J.E.B. Guirguis, S.S.F. Mehanny, Evaluating codes criteria for regular seismic behavior of continuous concrete box girder bridges with unequal height piers. ASCE J. Bridg. Eng. (2012). https://doi.org/10.1061/(ASCE)BE.1943-5592.0000383

5. Indian Road Congress, IRC 112: 2011-Code of Practice for Concrete Road Bridges (Indian Roads Congress, New Delhi, 2011)
6. J.E.B. Guirguis, S.S.F. Mehanny, How effective are EC8 and recommended AASHTO-LRFD criteria for regular seismic behavior of ductile bridges with unequal height piers?, in Proceedings of the 15th World Conference on Earthquake Engineering, Lisboa, 2012

7. Indian Road Congress, IRC 6: 2010-Standard Specifications and Code of Practice for Road Bridges Section: II, Loads and Stresses (Indian Roads Congress, New Delhi, 2010)

8. M.J.N. Priestley, G.M. Calvi, M.J. Kowalsky, DisplacementBased Seismic Design of Structures (IUSS Press, Pavia, 2007). ISBN 978-88-6198-000-6

9. ASHTO, American Association of State and Highway Transportation Officials LRFD Bridge Design Specifications (American Association of State Highway and Transportation Officials, Washington, 2012). ISBN: 978-1-56051-523-4

10. M.J.N. Priestley, Myths and Fallacies in Earthquake Engineering, Revisited (In the Ninth Mallet Milne Lecture) (Rose School, Pavia, 2003), pp. 9-31

11. American Concrete Institute, Building Code Requirements for Structural Concrete, ACI 318S-05 (American Concrete Institute, Farmington Hills, 2005)

12. Federal Emergency Management Agency, Prestandard and Commentary for the Seismic Rehabilitation of Buildings. Report FEMA 356, Washington DC, USA, 2000

13. T. Paulay, M.J.N. Priestley, Seismic Design of Reinforced Concrete and Masonry Buildings (Wiley, Hoboken, 1992)

14. J.R. Pique, M. Burgos, Effective rigidity of reinforced concrete elements in seismic analysis and design, in Proceedings of the 14th World Conference on Earthquake Engineering, Beijing, China, 2008

15. G.T. Halvorsen, Code Requirements for Crack Control, in Proceedings of the Lewis H. Tuthill International Symposium on Concrete and Concrete Construction, 104(15), 1987

16. P.H. Ziehl, J.E. Cloyd, M.E. Kreger, Evaluation of Minimum Longitudinal Reinforcement Requirements for Reinforced Concrete Columns, Report No. FHWA/TX-02/1473-S, Center for Transportation Research, University of Texas, Austin, 1998 